\title{
Oxidation of Aquatic Organic Contaminants Induced by Excited Triplet States
}

\author{
Silvio Canonica*
}

\begin{abstract}
The developments of the last fifteen years in the field of triplet-induced degradation of aquatic organic contaminants are reviewed. There is increasing evidence that the elusive excited triplet states of colored dissolved natural organic matter (CDOM) initiate the oxidative degradation of various contaminants. To date, phenols, phenylurea herbicides, and sulfonamide antibiotics have been shown to be affected by such an oxidation. The parallel study of aqueous oxidation of target contaminants induced by excited triplet states of aromatic ketones, taken as model systems, has been useful in understanding the action of triplet CDOM and in developing predictive tools to assess aquatic oxidation rates of such contaminants.
\end{abstract}

Keywords: Aromatic ketones · Dissolved organic matter · Electron transfer · Excited triplet states · Indirect phototransformation

\section{Introduction}

Excited triplet states of polyatomic organic molecules have now been studied for several decades. In this article, attention is focused on their role as oxidants in aerated aqueous solution and in the aquatic environment. Along with triplet-triplet energy transfer, hydrogen atom abstraction and electron transfer (to or from a reactant) are among the well-known bimolecular reactions involving excited triplet states. In general, because of the presence of unpaired electrons, an excited triplet state is a much better electron donor and electron acceptor than its parent molecule in the ground state. This property makes many organic chromophores attractive as light-activated reductants or oxidants. Before the start of our studies in this area in the early 1990s, hydrogen and electron abstraction reactions by excited triplet states

\footnotetext{
${ }^{*}$ Correspondence: Dr. S. Canonica

Eawag, Swiss Federal Institute of Aquatic Science and Technology

Überlandstrasse 133, P.O. Box 611

$\mathrm{CH}-8600$ Dübendorf

Tel.: +41448235453

Fax: + 41448235210

E-Mail: canonica@eawag.ch
}

had been already extensively studied under the name of 'photoreduction', ${ }^{[1-3]}$ and the great majority of investigations had been conducted in organic solvents. Photooxidation of substrates by excited triplet benzophenones in aqueous media was investigated to model oxidative damage in molecules of biological interest. ${ }^{[4-6]}$ The question arises whether similar processes can be relevant in environmental chemistry.

One of the important topics in aquatic photochemistry, which is the discipline that deals with photochemical reactions occurring in natural waters, is the study of the degradation of contaminants induced by light (terrestrial sunlight or ultraviolet and visible light from man-made sources used in engineered water treatment systems). In addition to the degradation following absorption of a photon by a target chemical contaminant and often referred to as 'direct photolysis' (or, more generally, 'direct phototransformation'), there exist a variety of photochemical reactions involving chromophores already present in natural waters and producing reactive species that initiate the degradation of the target contaminant ('indirect photolysis' or 'indirect phototransformation'). [7] Since the main absorber of light in natural waters is colored dissolved natural organic matter $(\mathrm{CDOM}),{ }^{[8,9]}$ a variable mixture of organic compounds and macromolecules derived from the metabolism and decomposition of living organisms, the possible involvement of excited triplet states of CDOM in indirect phototransformation of contaminants is obvious. $[10,11]$
The present paper is intended as a perspective article on the studies performed in the last one and a half decades to characterize the role of excited triplet states, in particular those of the CDOM, in the photooxidation of organic chemical contaminants in natural waters. The following questions are of central relevance: Are triplet-induced oxidations important for the fate of organic contaminants in the aquatic environment (environmental relevance)? Which classes of organic contaminants, or individual contaminants within a given chemical class, are more readily oxidized by excited triplet states? Is it possible to predict tripletinduced aquatic oxidation rates of organic contaminants?

\section{Excited Triplet States in Natural Waters}

Absorption of light by any organic chemical component of natural waters is likely to produce excited triplet states. Organic micropollutants themselves can form excited triplet states, but the reactivity of such triplets is not treated here because our interest is focused on the characterization of naturally occurring triplets. Moreover, in the great majority of natural waters, organic contaminants are present at much lower concentration than organic compounds of natural origin, and their role in defining the reactivity of natural waters may be neglected. CDOM of natural waters may be considered the main precursor of excited triplet states, 
whose basic chemistry is described in the following reaction scheme:

\begin{tabular}{|c|c|c|c|c|}
\hline CDOM & $+h v$ & $\rightarrow$ & ${ }^{1} \mathrm{CDOM}^{*}$ & \\
\hline${ }^{1} \mathrm{CDOM}^{*}$ & & $\rightarrow$ & ${ }^{3} \mathrm{CDOM}^{*}$ & \\
\hline${ }^{3} C D O M^{*}$ & & $\rightarrow$ & CDOM & \\
\hline${ }^{3} C D O M^{*}$ & $+\mathrm{O}_{2}$ & $\rightarrow$ & CDOM & $+\mathrm{O}_{2}$ \\
\hline${ }^{3} \mathrm{CDOM}^{*}$ & $+\mathrm{O}_{2}^{2}$ & $\rightarrow$ & $C D O M$ & $+{ }^{1} \mathrm{O}_{2}$ \\
\hline${ }^{3} C D O M^{*}$ & $+P^{2}$ & $\rightarrow$ & $C D O M^{\circ-}$ & $+\mathrm{P}^{\cdot+^{2}}$ \\
\hline $\begin{array}{l}C^{C D O M} M^{-} \\
{ }^{1} \mathrm{O}_{2}\end{array}$ & $+\mathrm{O}_{2}$ & $\vec{\rightarrow}$ & $\begin{array}{l}C D O M \\
\mathrm{O}_{2}\end{array}$ & $+\mathrm{O}_{2}^{\circ-}$ \\
\hline & & & & \\
\hline
\end{tabular}

Briefly, following absorption of a photon, CDOM chromophores reach their excited singlet manifold, ${ }^{1}$ CDOM* (Eqn. (1)), and subsequently, by intersystem crossing, their excited triplet state, ${ }^{3} \mathrm{CDOM}^{*}$ (Eqn. (2)). Intramolecular (Eqn. (3)) or oxygeninduced intermolecular deactivation of the triplet states (Eqns. (4),(5)) limits the lifetime of ${ }^{3} C D O M^{*}$ to at most $\approx 2 \mu$ s in aerated water at temperatures of $\approx 20^{\circ} \mathrm{C}$. A fraction of CDOM triplet states is still available to oxidize target contaminants (Eqn. (6)), and the reduced radicals of $\mathrm{CDOM}, \mathrm{CDOM}^{\circ}$, may be oxidized by oxygen forming the superoxide radical anion and regenerating CDOM (Eqn. (7)). As a result of triplettriplet energy transfer to ground state oxygen (Eqn. (5)), singlet oxygen is generated, which is deactivated by water (lifetime of $\approx 3-4 \mu \mathrm{s},{ }^{[12]}$ Eqn. (8)), but can also induce oxidation of the target contaminant (Eqn. (9)).

Singlet (molecular) oxygen $\left({ }^{1} \Delta_{\mathrm{g}}\right)$ is, together with hydroxyl radical, one of the best characterized photooxidants occurring in natural waters. Its significance for the degradation of contaminants was already recognized in the $1980 \mathrm{~s}^{[13-16]}$ and its aquatic chemistry has been subject of various review articles.[17-20] Owing to its high selectivity, singlet oxygen is probably decisive for the degradation of only a very restricted number of aquatic organic contaminants. ${ }^{[19,21]}$ However, since singlet oxygen and ${ }^{3} \mathrm{CDOM}^{*}$ are present in sunlit natural waters at comparable steady-state concentrations, ${ }^{[22]}$ when investigating triplet-induced transformations of contaminants one has always to consider a possible competitive oxidation by singlet oxygen.

The characterization of ${ }^{3} \mathrm{CDOM}^{*}$ appears to be a very difficult task owing to the great variety of chromophores (largely unidentified) present in CDOM. Direct observations of ${ }^{3} \mathrm{CDOM}^{*}$ are scarce and were obtained by nanosecond laser flash photolysis of aqueous humic substances.[17,23] Singlet oxygen formation has to be considered an important indirect evidence for the existence of excited triplet state precursors. Moreover, ${ }^{3} \mathrm{CDOM}^{*}$ were probed by triplet-triplet energy transfer using $(E)$ - and (Z)-1,3-cyclopentadiene, [22] which allowed the conclusion that up to half of such trip- lets had an energy of at least $250 \mathrm{~kJ} \mathrm{~mol}^{-1}$ and that typical steady-state concentrations of ${ }^{3} \mathrm{CDOM}^{*}$ near the surface of sunlit natural waters should lie in the range of $10^{-15}$ $10^{-13} \mathrm{M}$. These are very low concentrations, but still sufficient to produce contaminant half-lives of about one hour in the case of diffusion-controlled reactions. Investigations using time-resolved photoacoustic spectroscopy and magnetic circular dichroism spectroscopy revealed, for two aqueous fulvic acids, an average ${ }^{3} C D O M^{*}$ energy of $170-180 \mathrm{~kJ} \mathrm{~mol}^{-1}$ and intersystem crossing quantum yields (measured in the $\mathrm{pH}$ span of 2.5-9) in the 0.3-0.8 range. [24] What about the oxidizing capacity of ${ }^{3} C D O M^{*}$ ? Although the possibility of such oxidations was well-known and a corresponding mechanism had been postulated to be operative in the aquatic photodegradation of aniline, ${ }^{[25]}$ at the beginning of the 1990 s no systematic experimental investigation had been conducted in this area.

\section{Photosensitized Oxidation of Phenols}

A series of substituted phenols bearing electron-donating substituents, including the environmental endocrine disruptor 4-nonylphenol, were shown to be photooxidized in natural waters by not yet known reactive species derived from CDOM.[26] Oxidation by organic peroxyl radicals derived from CDOM was postulated, following the suggestion that these radicals were responsible, along with hydroxyl radical, for the photooxidation of organic contaminants in natural waters. ${ }^{[27]}$ A re-investigation of the topic with the aim of clarifying the nature of such unknown photooxidants by using chemically well-defined model systems led us to conclude that phenols were probably oxidized by excited triplet states and not by the formerly proposed peroxyl radicals. ${ }^{[28]}$ In an independent investigation, the reaction of excited triplet carbonyl compounds with phenols was proposed as a relevant source of hydrogen peroxide in atmospheric waters and aerosols. ${ }^{[29]}$ One of the main pieces of evidence in favor of the CDOM triplet hypothesis ${ }^{[28]}$ was that the selectivity of the photooxidation induced by CDOM (measured comparing pseudo-first-order depletion rate constants of the considered series of phenols under steady-state irradiation) fell in the range of selectivities obtained using three different aromatic ketone photosensitizers, namely benzophenone, 3'-methoxyacetophenone and 2-acetonaphthone (see structural formulae in Fig. 1). The study also revealed that, to improve the understanding of CDOM-induced photooxidations, a better characterization of the model systems was needed. This triggered the investigation of triplet quenching in aqueous solution for the three model aromatic ketones, ${ }^{[30]}$ which led to the following results:

i) Quenching rate constants and their trends (in terms of Hammett relationships) were markedly different in water from those previously obtained by others in organic solvents and aqueous solvent mixtures, ${ }^{[31,32]}$ benzophenone triplet being most effective and least selective in water.

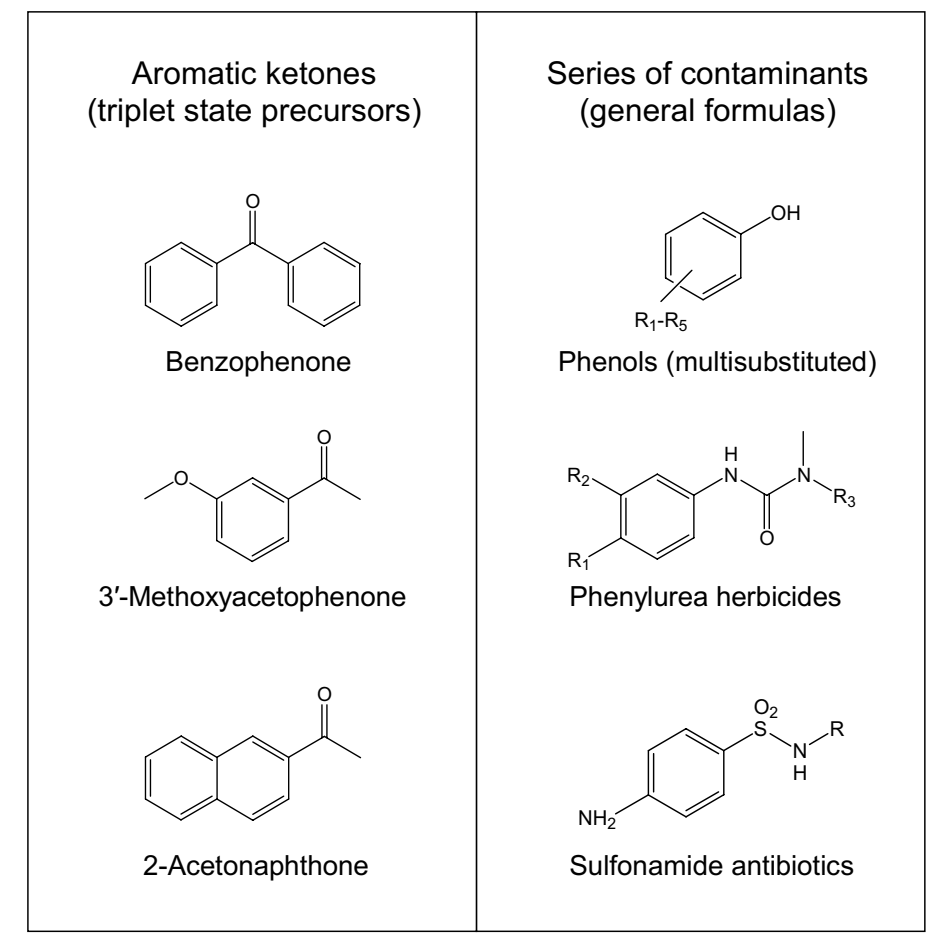

Fig. 1. Structural formulas of model excited triplet precursors and classes of contaminants discussed in this paper 
ii) Overall, the data (from 27 ketone-phenol pairs) could be well fitted to RehmWeller and Marcus relationships, indicating consistency with an electron transfer mechanism.

iii) There was good agreement in secondorder rate constants for quenching and phenol oxidation for the more electronrich phenols, while for phenols without electron-donating substituents oxidation rate constants were lower than the corresponding quenching rate constants.

An important conclusion was that aqueous photooxidation of phenols could only be most effective (i.e. occur at nearly diffusioncontrolled rate) when the standard one-electron reduction potential of the triplet ketone was higher than the corresponding potential for the couple $\left(\mathrm{P}^{\bullet+} / \mathrm{P}\right)$, where $\mathrm{P}$ and $\mathrm{P}^{\bullet+}$ stand for the target phenol and its radical cation, respectively. Is this principle valid for any excited triplet state, in particular those derived from CDOM, and any target organic compound? If it was, it would represent an important predictive tool to assess the triplet-induced photosensitized oxidation of organic contaminants in natural waters - a significant component in environmental risk analysis. ${ }^{[33]}$

\section{Photosensitized Oxidation of Pesticides and Pharmaceuticals}

Phenylurea herbicides (PUHs) are present in surface waters as a consequence of extensive use in agriculture and urban areas (see ref. [34] and references therein), and interest arose about the assessment of their fate and impact in rivers and lakes. Photochemical studies on aqueous fenuron, monuron and diuron, three representative PUHs, in the presence and absence of dissolved humic substances confirmed that CDOMphotosensitized transformation was taking place ${ }^{[35-37]}$ and ${ }^{3} C D O M^{*}$ was proposed as one of the active oxidant species initiating the transformation. An investigation combining photochemical experiments, analytical monitoring and mathematical modeling of transport and chemical transformation in the Swiss lake Greifensee could show that, for isoproturon and diuron, CDOM-photosensitized transformation was probably the major process leading to their elimination from the aquatic environment. ${ }^{[38]}$ Kinetics tests led us to exclude the participation of singlet oxygen and postulate involvement of ${ }^{3} \mathrm{CDOM}^{*}$ in the degradation of isoproturon. ${ }^{[38]}$ Moreover, the reactivity of a series of eleven PUHs using Suwannee River fulvic acid, a well-characterized reference humic substance, as CDOM photosensitizer presented a strikingly similar trend and extent to the reactivity previously observed with phenols. A comparison of such reactivities based on Hammett $\sigma^{+}$constants (determined for phenols and PUHs taking as reference compound phenol and fenuron, respectively) is shown in Fig. 2a. In the same manner as undertaken with the phenols, the reaction of PUHs with the excited triplet states of the model aromatic ketones was investigated by measuring triplet quenching and PUHs depletion rate constants. ${ }^{[39]}$ Triplet 2-acetonaphthone turned out to have no detectable reactivity, while interaction with triplet benzophenone was almost diffusion-controlled for all PUHs. Triplet 3'-methoxyacetophenone displayed an intermediate behavior, which is shown in Fig. 2b. PUHs exhibit, as found for the fulvic acid, a reactivity which is slightly lower than that of the phenols, probably indicating that the phenyl substituent group $-\mathrm{N}-\mathrm{C}(\mathrm{O})-\mathrm{N}\left(\mathrm{CH}_{3}\right)_{2}$ is a weaker electron donor than the group -OH. Unfortunately, a quantitative analysis in terms of electron transfer theory could not be performed for the PUHs owing to complete lack of data on aqueous standard reduction potentials. However, if one assumes the same oxidation mechanism to hold for the model aromatic ketones and for CDOM, from the phenols and PUHs reactivities it is possible to estimate the standard one-electron reduction potential of ${ }^{3} C D O M^{*}$. This should be higher than that of triplet 2-acetonaphthone, i.e. $1.34 \mathrm{~V} v s$. NHE (normal hydrogen electrode), but lower than that of triplet benzophenone, i.e. $1.79 \mathrm{~V} v$ s. NHE (values calculated from literature values $\left.{ }^{[40]}\right)$, and close to that of 3'-methoxyacetophenone, which is not known in pure water but should be $\approx 1.7 \mathrm{~V} v s$. NHE (it is $1.64 \mathrm{~V} v s$. NHE in a water/ethanol mixture $\left.{ }^{[41]}\right)$.

Sulfonamides, used as antibiotics in human and veterinary medicine, constitute a further series of homologous compounds subject to CDOM-photoinduced transformation, most probably by excited triplet states.[42] Four out of five sulfonamide derivatives (see the general structural formula in Fig. 1) bearing a six-membered heterocyclic group reacted with photoexcited CDOM and all of them with photoexcited 3'-methoxyacetophenone, giving rise to an $\mathrm{SO}_{2}$ extrusion photoproduct. Such sulfonamides can be viewed as anilines bearing a sulfonamide substituent in para position. The sulfonamide group $\left(-\mathrm{SO}_{2} \mathrm{NH}_{2}\right)$ is slightly less electron-withdrawing than the cyano group (Hammett $\sigma_{\mathrm{p}}$ constants of 0.60 and 0.66 , respectively[43]), which leads, by applying a known Hammett relationship for the redox potential of anilines, ${ }^{[44]}$ to an estimated reduction potential for the couple $\left(\mathrm{P}^{++} / \mathrm{P}\right)$ of $1.22 \mathrm{~V} v s$. NHE. This is much less than the reduction potential of $\approx 1.7 \mathrm{~V} v s$. NHE for ${ }^{3} C D O M^{*}$ (see the estimation performed above), which let us conclude that electron transfer from the sulfonamides to ${ }^{3} \mathrm{CDOM}^{*}$ should be very effective.
Fig. 2. a) Pseudo-firstorder rate constants, relative to $2,4,6$ trimethylphenol, for the depletion of phenols and phenylureas photosensitized by Suwannee River fulvic acid, and b) secondorder rate constants for triplet quenching (full symbols) and contaminant depletion (open symbols) photoinduced by 3'methoxyacetophenone. Data are taken from refs. $[28,30,38,39]$. The sum of Hammett $\sigma^{+}$constants was calculated with respect to the basic structures displayed in Fig. 1 (with $\mathrm{R}_{3}=\mathrm{CH}_{3}$ for the phenylureas) using the method described in ref. [48].

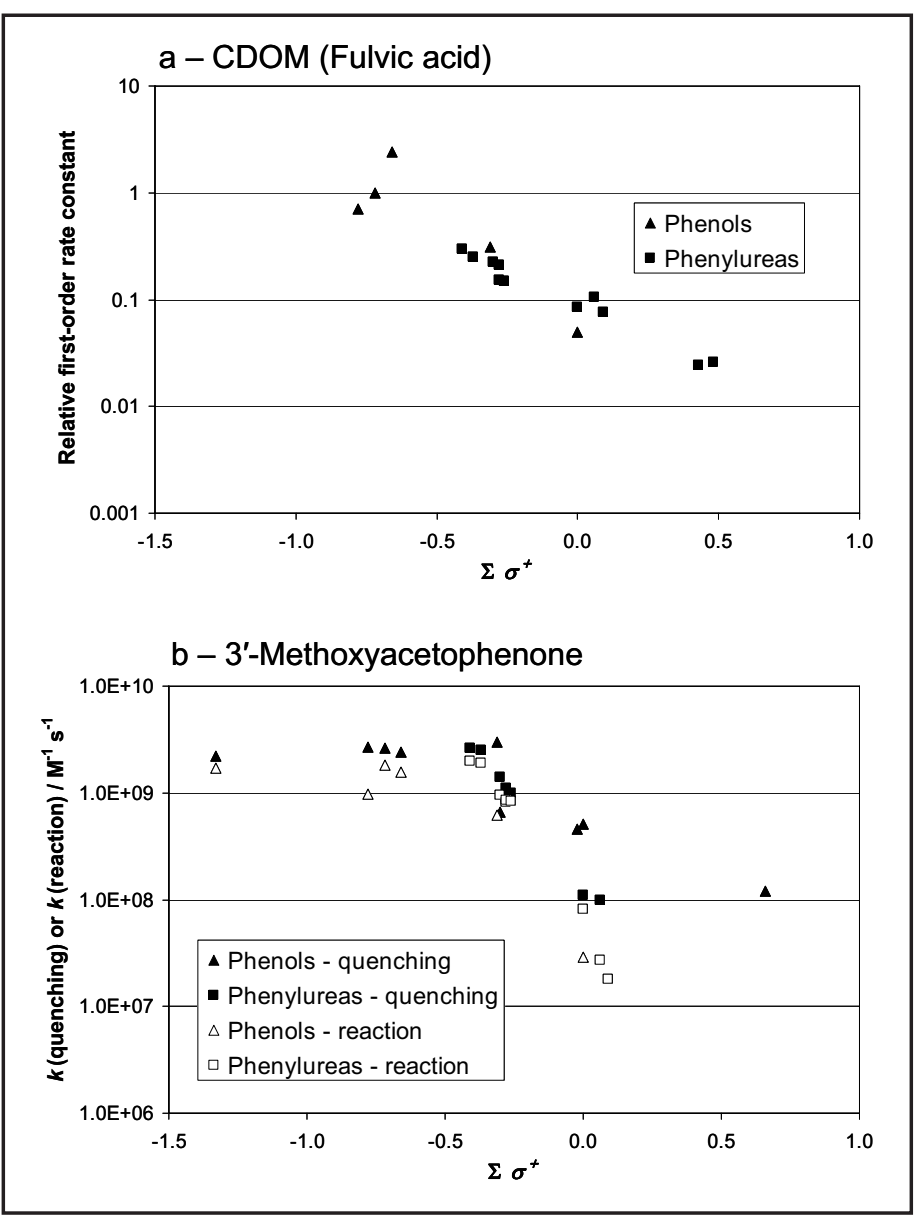


Mefenamic acid, a diphenylamine derivative used as an algesic and anti-inflammatory drug, also exhibited a CDOM-induced phototransformation amenable to oxidation by excited triplet states. ${ }^{[45]}$ The list of environmentally relevant compounds degradable by oxidative excited triplet states of CDOM is steadily increasing and includes estrogendisrupting compounds such as bisphenol $\mathrm{A},{ }^{[46,47]}$ a high production volume chemical used in the synthesis of polycarbonates, and possibly the contraceptive $17 \alpha$-ethinylestradiol (work in progress).

\section{Assessment of Aquatic Degradation Rates}

The Marcus and Rehm-Weller equations, as applied to the triplet-induced oxidation of phenols, ${ }^{[30]}$ are promising tools to assess electron transfer rates from, and finally oxidation rates of organic contaminants in aquatic systems. Owing to the ubiquity of the hydroxyl radical in sunlit and UV-irradiated waters, a relevant contribution of excited triplet state oxidants to contaminant degradation is limited to those reactions occurring at relatively high rates ${ }^{[33]}$ (second-order rate constants higher than $\approx 10^{7} \mathrm{M}^{-1} \mathrm{~s}^{-1}$ ). Once a compound has been identified as potentially highly reactive to ${ }^{3} \mathrm{CDOM}^{*}$, the effectiveness of its oxidation should be checked. There are indeed many different factors that could hamper oxidation even if the first oxidative step is energetically allowed. Competitive reactions between the excited triplet state and the target contaminant, $\mathrm{P}$, such as photophysical triplet deactivation and triplet-triplet energy transfer, might significantly lower the formation yield of the oxidized primary radical, $\mathrm{P}^{\bullet+}$, and thus the rate of oxidation of $\mathrm{P}$. In addition, even in the presence of a high yield of $\mathrm{P}^{\bullet+}$, the latter might undergo reduction to its parent compound thus lowering the net oxidation rate. Such reduction processes are possible in natural waters owing to the presence of natural organic matter, which also includes components acting as antioxidants. For instance, reduction of oxidation intermediates were proposed to play an important role in the carbonate-radical induced oxidation of anilines. ${ }^{[48]}$ Therefore, in the case of predicted high reactivity with ${ }^{3} C D O M^{*}$, oxidation rates of contaminants of environmental concern should be carefully measured under appropriate conditions.

\section{Conclusions}

Excited triplet states of colored dissolved natural organic matter $\left({ }^{3} \mathrm{CDOM}{ }^{*}\right)$ appear to play a crucial role in the oxidation of organic contaminants in surface waters and UV-irradiated natural waters. Phenols, phenylureas and 4-amino-benzenesulfonamides have been identified so far as important classes of compounds particularly subject to such an oxidation. The use of model photosensitizers, specifically aromatic ketones, provides insight into the aqueous oxidation of organic contaminants by excited triplet states and into the reactivity of CDOM triplet states.

Received: July 27, 2007

[1] J. C. Scaiano, J. Photochem. 1973, 2, 81.

[2] S. G. Cohen, A. Parola, G. H. Parsons, Chem. Rev. 1973, 73, 141.

[3] P. J. Wagner, Top. Curr. Chem. 1976, 66, 1.

[4] M. V. Encinas, E. A. Lissi, A. F. Olea, Photochem. Photobiol. 1985, 42, 347.

[5] M. V. Encinas, E. A. Lissi, M. Vasquez, A. F. Olea, E. Silva, Photochem. Photobiol. 1989, 49, 557.

[6] K. Bobrowski, B. Marciniak, G. L. Hug, J. Am. Chem. Soc. 1992, 114, 10279.

[7] O. C. Zafiriou, J. Joussot-Dubien, R. G. Zepp, R. G. Zika, Environ. Sci. Technol. 1984, 18, A358.

[8] S. A. Green, N. V. Blough, Limnol. Oceanogr. 1994, 39, 1903.

[9] N. V. Blough, S. A. Green, in 'Role of Nonliving Organic Matter in the Earth's Carbon Cycle', Eds. R. G. Zepp, C. Sonntag, John Wiley \& Sons Ltd., Chichester, U. K., 1995, p. 23.

[10] R. G. Zepp, G. L. Baughman, in 'Aquatic pollutants: Transformation and biological effects', Eds. O. Hutzinger, I. H. Van Lelyveld, B. C. J. Zoeteman, Pergamon Press, Oxford, U.K., 1978, p. 237.

[11] G. G. Choudhry, A. A. M. Roof, O. Hutzinger, Toxicol. Env. Chem. Rev. 1979, 2, 259.

[12] F. Wilkinson, W. P. Helman, A. B. Ross, $J$. Phys. Chem. Ref. Data 1995, 24, 663.

[13] R. G. Zepp, G. L. Baughman, P. F. Schlotzhauer, Chemosphere 1981, 10, 119.

[14] W. R. Haag, J. Hoigne, E. Gassman, A. M. Braun, Chemosphere 1984, 13, 631.

[15] W. R. Haag, J. Hoigne, E. Gassman, A. M. Braun, Chemosphere 1984, 13, 641.

[16] W. R. Haag, J. Hoigné, Environmental Science \& Technology 1986, 20, 341.

[17] W. J. Cooper, R. G. Zika, R. G. Petasne, A. M. Fischer, $A d v$. Chem. Ser. 1989, 219, 333.

[18] J. Hoigné, in 'Aquatic Chemical Kinetics: Reaction Rates of Processes in Natural Waters', Ed. W. Stumm, Wiley-Interscience, New York, 1990, p. 43.

[19] R. A. Larson, K. A. Marley, in 'The Handbook of Environmental Chemistry', Ed. O. Hutzinger, Springer, Berlin, Germany, 1999, Vol. 2, Part L, p. 123

[20] B. C. Faust, in 'The Handbook of Environmental Chemistry', Ed. O. Hutzinger, Springer, Berlin, Germany, 1999, Vol. 2, Part L, p. 101.

[21] C. Richard, S. Canonica, in 'The Handbook of Environmental Chemistry', Ed. O. Hutzinger, Springer, Berlin, Germany, 2005, Vol. 2, Part M, p. 299.
[22] R. G. Zepp, P. F. Schlotzhauer, R. M. Sink, Environ. Sci. Technol. 1985, 19, 74.

[23] J. F. Power, D. K. Sharma, C. H. Langford, R. Bonneau, J. Joussot-Dubien, ACS Symposium Ser. 1987, 327, 157.

[24] A. Bruccoleri, B. C. Pant, D. K. Sharma, C. H. Langford, Environ. Sci. Technol. 1993, 27, 889.

[25] R. G. Zepp, G. L. Baughman, P. F. Schlotzhauer, Chemosphere 1981, 10, 109.

[26] B. C. Faust, J. Hoigne, Environ. Sci. Technol. 1987, 21, 957.

[27] T. Mill, D. G. Hendry, H. Richardson, Science 1980, 207, 886.

[28] S. Canonica, U. Jans, K. Stemmler, J. Hoigné, Environ. Sci. Technol. 1995, 29, 1822.

[29] C. Anastasio, B. C. Faust, C. J. Rao, Environ. Sci. Technol. 1997, 31, 218.

[30] S. Canonica, B. Hellrung, J. Wirz, Phys. Chem. A 2000, 104, 1226.

[31] P. K. Das, M. V. Encinas, J. C. Scaiano, J. Am. Chem. Soc. 1981, 103, 4154.

[32] P. K. Das, S. N. Bhattacharyya, J. Phys. Chem. 1981, 85, 1391.

[33] K. Fenner, S. Canonica, B. I. Escher, L. Gasser, S. Spycher, H. C. Tulp, Chimia 2006, 60, 683 .

[34] A. C. Gerecke, C. Tixier, T. Bartels, R. P. Schwarzenbach, S. R. Muller, J. Chromatogr. A 2001, 930, 9.

[35] J. P. Aguer, C. Richard, Pestic. Sci. 1996, 46, 151.

[36] C. Richard, D. Vialaton, J. P. Aguer, F. Andreux, J. Photochem. Photobiol. A-Chem. 1997, 111, 265.

[37] J. P. Aguer, C. Richard, Chemosphere 1999, 38, 2293.

[38] A. C. Gerecke, S. Canonica, S. R. Müller, M. Schärer, R. P. Schwarzenbach, Environ. Sci. Technol. 2001, 35, 3915.

[39] S. Canonica, B. Hellrung, P. Müller, J. Wirz, Environ. Sci. Technol. 2006, 40, 6636.

[40] I. Loeff, J. Rabani, A. Treinin, H. Linschitz, J. Am. Chem. Soc. 1993, 115, 8933.

[41] A. J. G. Barwise, A. A. Gorman, R. L. Leyland, P. G. Smith, M. A. J. Rodgers, J. Am. Chem. Soc. 1978, 100, 1814.

[42] A. L. Boreen, W. A. Arnold, K. McNeill, Environ. Sci. Technol. 2005, 39, 3630.

[43] C. Hansch, A. Leo, R. W. Taft, Chem. Rev. 1991, 91, 165.

[44] S. Canonica, P. G. Tratnyek, Environ. Toxicol. Chem. 2003, 22, 1743.

[45] J. J. Werner, K. McNeill, W. A. Arnold, Chemosphere 2005, 58, 1339.

[46] Y. P. Chin, P. L. Miller, L. K. Zeng, K. Cawley, L. K. Weavers, Environ. Sci. Technol. 2004, 38, 5888.

[47] M. J. Zhan, X. Yang, Q. M. Xian, L. G. Kong, Chemosphere 2006, 63, 378.

[48] S. Canonica, T. Kohn, M. Mac, F. J. Real, J. Wirz, U. Von Gunten, Environ. Sci. Technol. 2005, 39, 9182. 